\title{
O NOVO JÁ NASCE VELHO: BREVE ANÁLISE SOBRE DOIS MOVIMENTOS POLÍTICOS
}

\author{
The New Is Already Old: a brief analysis of two political movements
}

Eneida Desiree Salgado

Iago Korello dos Santos

Wesley Alves Bergonzine

Resumo: Partindo da premissa de que a representação política e o sistema partidário estão em crise, uma nova - ou nem tão nova assim - alternativa para a apresentação de propostas políticas e alternativas ao eleitorado se coloca no cenário nacional seguindo as chamadas "Jornadas de junho de 2013". As manifestações com seus lemas por vezes contraditórios acabaram identificadas com um discurso antipolítico e deixaram como herança movimentos políticos. Dois deles são analisados neste artigo: o Movimento Brasil Livre (MBL) e o Renova Brasil. A escolha dessas duas organizações se deve (i) à importância durante e depois das jornadas de junho; e (ii) à eleição de alguns de seus membros por partidos políticos diversos. Embora se apresentem como algo novo na política, os discursos políticos e as estratégias parecem aproximá-los de organizações que atuaram no Brasil na antessala da ruptura constitucional dos anos 1960. Além disso, os movimentos políticos podem representar uma fuga do regime jurídico-constitucional aplicado aos partidos políticos, o que traria um desequilíbrio na disputa eleitoral. O estudo termina por indicar a necessidade de transparência e controle sobre os recursos desses movimentos e sobre sua atuação.

Palavras-chave: Movimentos políticos. Partidos políticos. Jornadas de junho de 2013. Movimento Brasil Livre. Renova Brasil.

\begin{abstract}
Based on the premise that political representation and the party system in Brazil are in crisis, a new - or not so new - alternative for presenting political and unconventional proposals to the electorate is placed on the national scene following the demonstrations that occurred throughout the country in June 2013. With their sometimes contradictory mottos, the demonstrations identified with an anti-political discourse and left political movements as their legacy. We analyze two movements in this article: the Movimento Brasil Livre (MBL) and Renova Brasil. This choice is due to (i) their importance during and after the June 2013 demonstrations and (ii) the fact that some of their members registered in different political parties and were elected. Although they present themselves as something new in politics, political discourses and strategies nevertheless seem to bring these novelties closer to organizations that acted in Brazil in the anteroom of the constitutional rupture of the 1960s. In addition, political movements may escape the legal-constitutional regime applied to political parties, bringing an imbalance in the electoral dispute. The study concludes indicating the need for transparency and control over the performance and the resources of the new political movements.
\end{abstract}

Keywords: Political movements. Political parties. June 2013 demonstrations. Movimento Brasil Livre. Renova Brasil.

Artigo recebido em 13 out. 2020 e aprovado em 21 out. 2020. 


\section{Introdução: mais do mesmo, mesmo do mais, ou muito pelo contrário?}

Os partidos políticos estão em crise, há uma crise de representação política, a democracia está se erodindo e chegou a um ponto crítico. Esse diagnóstico é tema corrente entre analistas da política, nos debates parlamentares, nas deliberações judiciais, nos editoriais jornalísticos e nos eventos e artigos acadêmicos, e não se trata de uma novidade.

A baixa credibilidade dos partidos políticos está estampada na discussão entre federalistas e antifederalistas na formação dos Estados Unidos. No Brasil Império, os partidos políticos não eram marcadamente diferentes em sua atuação, e um dos ditados políticos mais presentes afirmava que "nada se assemelha mais a um Saquarema do que um Luzia no poder...", fazendo referência a representantes conservadores e liberais, respectivamente.

A crise da representação política existe desde que o corpo representado passou a ser heterogêneo. A inclusão de não proprietários, não brancos, não cristãos, não homens no corpo eleitoral leva a demandas concorrentes, impossíveis de serem todas atendidas pela representação política. O fim do mandato imperativo e de suas instruções como elemento necessário da relação de representação faz desaparecer um conteúdo pré-determinado do mandato e, desde então, parte do eleitorado sempre se sente ignorado pelas decisões do corpo representante.

E a democracia - pelo menos no Brasil - nunca foi defendida bravamente por toda a sua população. As sucessivas rupturas institucionais e o desapego ao texto constitucional por parte dos agentes públicos e de quem exerce o poder estão explícitos desde o golpe da maioridade em 1840 ao golpe parlamentar de 2016. Aliás, a gramática antidemocrática de quando em quando aparece em discursos políticos e projetos legislativos, além de vez ou outra aparecer também em decisões judiciais.

Há, ainda, um crescente discurso de criminalização da política, inicialmente travestido de combate à corrupção. Operações policiais capitaneadas por órgãos de controle atacam pessoas políticas e partidos, em um caldo que retroalimenta a descrença nas potencialidades da democracia eleitoral. Um moralismo eleitoral que corrói direitos fundamentais e que abre espaço para discursos e alternativas que se colocam como antipolítica, antipartidos e, ao fim, antidemocrático. E uma das coisas que (re)surgem no cenário são os movimentos políticos. 


\section{O gigante acordou, com uma esperança equilibrista em um falso brilhante}

Em junho de 2013, uma onda de manifestações populares reuniu mais de um milhão de pessoas em 12 capitais brasileiras e em outras cidades de médio porte. Eventos similares em proporção de pessoas só foram vistos no Brasil em 1992, com o impeachment do ex-presidente Collor de Mello; em 1984, com o movimento Diretas Já, no período do regime militar, na luta pelo retorno à democracia; e nos anos de 1960, com as greves e paralisações pré-golpe militar de 1964, e nas passeatas estudantis de 1968 (GOHN, 2014; PINHEIRO-MACHADO, 2019).

Os eventos ocorridos em junho de 2013 foram denominados "manifestações", e expressavam "estados de indignação face à conjuntura política nacional", de acordo com Maria da Glória Gohn. Refletem uma nova forma de movimento social que aglutina a indignação de classes sociais diferentes, mas com predomínio da classe média e dos jovens. Além disso, são caracterizados pela conexão em redes digitais com organização horizontal e autônoma, além da crítica às formas tradicionais da política especialmente quanto aos partidos e sindicatos (GOHN, 2014, p. 431).

$\mathrm{Na}$ esteira de protestos, como os ocorridos na chamada "Primavera Árabe", intensificou-se, principalmente a partir de 2009, o uso das Novas Tecnologias de Informação e Comunicação (NTICs) ${ }^{1}$, fazendo com que as redes sociais virtuais (Online Social Network) $)^{2}$ ficassem marcadas por funções específicas (CAVALCANTI, 2019). Nesse sentido, o Twitter aparece como ferramenta para a disseminação de informações em tempo real, o Youtube para o upload e divulgação de conteúdos, enquanto o Facebook promovia discussões, vídeos, eventos e imagens. Já o WhatsApp mobiliza pessoas com seus grupos, e o Instagram é outro meio utilizado por ativistas políticos.

Essa espécie de manifestação que "varreu o mundo" nos últimos anos é permeada por uma disputa narrativa (PINHEIRO MACHADO, 2019; MESSAGI JUNIOR, 2019; SAVAZONI, 2014). No Brasil, caracte-

\footnotetext{
${ }^{1}$ Desenvolvidas desde a década de 1970, as NTICs são entendidas como recursos tecnológicos que proporcionam, por meio das funções de software, hardware e telecomunicações, o funcionamento de processos de comunicação, de negócios e pesquisas, entre outros.

${ }^{2}$ Entre as OSN mais conhecidas estão redes de amigos (Facebook), profissionais (ex., LinkedIn), de mensagens privadas (WhatsApp) e de compartilhamento de conteúdos por mensagens, vídeos e fotos (Twitter, Youtube e Flickr, respectivamente).
}

Resenha Eleitoral (Florianópolis), v. 24, n. 2, p. 15-42, 2020 
rizou-se pela composição de dois grupos: jovens de esquerda, que reivindicam mais direitos e uma maior tutela do Estado; e uma grande massa de pessoas contrárias à presença do Estado e, até mesmo, à luta por direitos, em uma espécie de antimilitância (MESSAGI JUNIOR, 2019).

Junho de 2013 é a eclosão de uma crise institucional pela qual o Brasil vinha passando na década anterior, em que a insatisfação e a falta de espaços de compartilhamento das divergências desembocaram em manifestações cuja dinâmica é a mesma verificada na internet e nas redes sociais, isto é, com um ambiente mais igualitário e horizontal (MESSAGI JUNIOR, 2019).

Segundo Messagi (2019), no processo de interpretação desse evento, a grande mídia, a princípio, não soube como reagir, assim como todos os atores de junho de 2013, tendo direcionado, num segundo momento, a insatisfação popular para o governo federal, cooptando a indignação popular para os interesses de determinado espectro político ao utilizar-se do discurso da "anticorrupção". Esse fator foi decisivo frente à inoperância dos partidos políticos, que não sabiam como abarcar as demandas trazidas pelas manifestações, e reforçou a crise do sistema político, conferindo às manifestações um caráter mais conservador do que verificado em seu início (MESSAGI JUNIOR, 2019).

$\mathrm{Na}$ mesma linha, Avritzer (2017) aponta que, naquele cenário, imediatamente teve início um processo de diferenciação que expandiu as preocupações dos manifestantes para a questão da corrupção, dando enfoque ao Partido dos Trabalhadores (PT) e ao governo federal como as fontes da corrupção a ser enfrentadas. A participação política, tradicionalmente protagonizada por grupos mais populares, passou a ser encampada com maior centralidade pelas classes médias, culminando em uma hegemonia dos setores conservadores em 2015.

A par deste debate a respeito do espectro político-ideológico das manifestações de junho de 2013 e dos movimentos políticos que lhes sucederam, tais como o Movimento Brasil Livre e o Renova Brasil, é possível afirmar que as novas tecnologias digitais e o colaboracionismo, que marcam esses movimentos, juntam pessoas no mundo simbólico e no mundo real para diferentes finalidades, o que dificulta o estabelecimento de um consenso sobre seus sentidos político, cultural ou econômico. Contudo, uma causa parece ser comum a eles: a liberdade na internet e a circulação livre de informações, feitas de forma multidirecional. Isso abala o mundo político consolidado, que está e estará sujeito a outros eventos que colocam em xe- 
que o atual modelo de representação - e a própria democracia -, enquanto a internet permanecer com tais características (MESSAGI JUNIOR, 2019).

Os partidos, enquanto principais atores do mundo político, há tempos apresentam baixos resultados em relação à confiança perante a opinião pública. Essa falta de credibilidade está demonstrada nos números que o Índice de Confiança Social (ICS) ${ }^{3}$ apresenta. Segundo o ICS, de 2009 a 2017, os partidos políticos figuraram entre as organizações em que a população menos confiou, numa avaliação de 20 instituições. Desde 2009 (início das medições), os partidos permanecem na última colocação no referido índice.

Considerando os dados do Latinobarômetro, os partidos políticos em 2018 foram as instituições com menor confiança na América Latina, com apenas 13\% de confiança. Nessa pesquisa, o Uruguai apresenta o maior resultado com $21 \%$, enquanto o Brasil apresenta o segundo pior indicador da região, com apenas $6 \%$ de confiança (CORPORACIÓN LATINO BARÓMETRO, 2018) ${ }^{4}$.

Diante desse quadro, alguns dos partidos políticos quiseram se mostrar atualizados com o novo tempo, modificando sua imagem com o abandono da palavra "partido" em suas denominações. Esse rebranding pode ser lido como um movimento de reconhecimento das suas dificuldades e estigmas negativos. Apesar da superficialidade da estratégia, os partidos vêm buscando se distanciar justamente do que os distingue de qualquer outra organização com atividade política. Vários exemplos são observados no Brasil, desde a mudança do Partido da Frente Liberal para Democratas (2007) e da criação do Solidariedade (2013), do Novo (2015) e da Rede Sustentabilidade (2015), a tendência de exclusão da famigerada palavra "partido” parece ter emplacado. O Partido do Movimento Democrático Brasileiro voltou a ser Movimento Democrático Brasileiro; o Partido Trabalhista do Brasil tornou-se Avante; o Partido Trabalhista Nacional é Podemos; o Partido Ecológico Nacional se chama agora Patriota; o Partido Progressis-

\footnotetext{
${ }^{3}$ O ICS é pesquisa anual produzida pelo Ibope Inteligência para monitorar a evolução da confiança da população em instituições e grupos sociais. Disponível em: <https://www. ibopeinteligencia.com/arquivos/JOB\%2019_0844_ICS_INDICE_CONFIANCA_SOCIAL_/>. Acesso em: 19 jul. 2020.

${ }^{4}$ CORPORACIÓN LATINO BARÓMETRO. Relatório do Latinobarômetro 2018. Santiago, Chile. 2018. Disponível em: <https://www.latinobarometro.org/lat.jsp>. Acesso em: 19 jul. 2020.
} 
ta é Progressistas; o Partido da Social Democrata Cristão mudou o nome para Democracia Cristã; o Partido Republicano Brasileiro para Republicanos; e o Partido Popular Socialista para Cidadania.

Essa estratégia também está relacionada à disseminação de discursos que transmitem um sentimento de antipolítica e de aversão aos políticos, sem distinções entre mandatários e não mandatários, criando um paradoxo que envolve uma indignação do corpo eleitoral com suas próprias escolhas, que sempre podem ser revistas a cada quatro anos. Nesse sentido, o surgimento dos novos movimentos parece ser mais uma ocupação da lacuna de desconfiança deixada pelos partidos do que uma novidade capaz de superá-los, na medida em que compartilham muitos objetivos, tal como a busca por mandatos representativos.

O discurso da antipolítica abarca diferentes enfoques, que prevalece sobre certo alvo a depender do movimento. Contudo, existe um fio condutor comum a todos. Conforme explica Gohn (2014), o que motiva esses movimentos é um sentimento de descontentamento e indignação contra a conjuntura ético-política de dirigentes e representantes civis eleitos, nas estruturas de poder estatal. O Movimento Passe Livre compartilha tal sentimento, declarando-se apartidário, embora não antipartidário; seus integrantes querem renovar a política, o tipo de partidos e políticos atuais. Por isso, o tema de uma reforma política não os atraiu imediatamente, pois seria feita pelos políticos de então, os quais eles contestam (GOHN, 2014).

Qualquer que seja sua inclinação ideológica, um diagnóstico parece reunir esses movimentos: o de que há tempos os partidos políticos deixaram de atuar como ferramentas de formação de consenso, e perderam a aptidão para propiciar um ambiente político dinâmico e funcional. Essa atuação cada vez mais está a cargo do mercado, da indústria publicitária, do marketing, dos espaços virtuais e das redes sociais (NOGUEIRA, 2019). No contexto do mundo ocidental, a abstenção eleitoral chega a ultrapassar um quarto do eleitorado, e esse ambiente abre espaço para políticos personalistas com discursos demagogos, criando-se agitamento descontrolado das redes sociais e dos cidadãos, que sentem cada vez menos que podem alcançar a tutela do Estado (NOGUEIRA, 2019).

Apesar da responsabilização dos partidos pelas insuficiências ante as demandas sociais contemporâneas, há outros elementos externos às legendas que contribuem para esse cenário de dificuldades. As decisões políticas não têm sua legitimidade assegurada apenas pelo processo democráti- 
co formal. A democracia representativa não permite ao povo nada além de escolher quem irá tomar as decisões (SALGADO, 2014), não representando de fato uma ferramenta que assegura ao povo a soberania prevista pela Constituição Federal. O desenho democrático representativo, portanto, apresenta falhas, que estão para além do papel das legendas.

Para Nogueira (2019), enquanto a política institucionalizada aprofunda laços com o sistema econômico-financeiro e retorna a um modus operandi oligárquico que renega os cidadãos, os novos movimentos apresentam novas formas de organização e de representação. $\mathrm{O}$ autor considera que esses movimentos representam uma resposta à crise do sistema, na qual os partidos se enfraquecem, as instituições perdem sua legitimidade e os eleitores se afastam do processo eleitoral.

Contudo, diferentemente do que sustenta Nogueira (2019), observa-se que, não obstante se apresentem como novidade e contraponto ao modelo partidário, os novos movimentos políticos não estão muito distantes dessa relação com o sistema econômico-financeiro. Ademais, também buscam se integrar à vida política institucional, na medida em que apresentam candidaturas a cargos eletivos, demonstrando que seu advento não consiste numa proposta efetivamente exógena ao modelo representativo partidário, como podem sugerir seus discursos.

\section{O que há algum tempo era novo, jovem, hoje é antigo: um olhar sobre novos atores}

Nesse cenário, em que há uma intensa crise da representação e um desgaste do sistema político partidário, o advento de novos movimentos políticos não parece ser apenas um efeito natural, mas uma oportunidade para escapar às obrigações ou limitações legais impostas aos partidos. Apesar disso, e, embora promovam um discurso que varia da antipolítica ao apartidário, os movimentos têm conseguido o apoio das legendas para concorrerem aos cargos de representação, já que os partidos querem capitalizar a boa imagem que eles têm perante a opinião pública.

Dois movimentos que surgiram a partir de junho de 2013 serão analisados de maneira detida: o Renova Brasil e o Movimento Brasil Livre. O Renova Brasil, ou RenovaBR, busca engajar e mobilizar a audiência com enquadramentos que os apresentam como atores fora da política institu- 
cional, enfatizando a necessidade de mudança e se colocando como atores anti-establishment por meio do discurso da renovação.

O Movimento tem como fundador o empresário Eduardo $\mathrm{Mu}-$ farej, sócio da Tarpon Investimentos e presidente da Somos Educação. A iniciativa teve apoio de empresários e figuras públicas, como Abílio Diniz, Armínio Fraga e Luciano Huck. O Movimento busca se caracterizar como organização formal em que se define por diferentes formas, sem assumir uma identidade organizacional muito clara (FOLHA DE SÃO PAULO, $2018)^{5}$.

Para Moura (2019), as características de movimentos de renovação política, se alinham a três aspectos organizacionais: a) uso de redes formais e informais, promovendo ações de mobilização e engajamento da sociedade civil para ação coletiva; b) na forma de organizações voluntárias, promovem serviços como a formação de seus membros e apoio para suas candidaturas; c) e tal qual ONGs, adotam agendas de políticas públicas e possuem uma organização profissionalizada. Vale destacar ainda que são movimentos que, em parte, possuem relação direta com empresários e profissionais liberais, os quais são os responsáveis pelo provimento e levantamento de recursos financeiros para consecução de seus objetivos.

A atuação do Movimento mira a seleção/recrutamento de candidatos; formação para a disputa eleitoral e exercício de mandato; acompanhamento dos líderes, como são chamados os seus membros, "durante e depois da formação, recebendo suporte e se conectando com pessoas de valores semelhantes". Se eleitos, os líderes se comprometem em "manter a honestidade, a transparência, finalizar o mandato e debater ações de impacto", conforme afirmam em sua página virtual.

As lideranças selecionadas dispõem de bolsas para ajudas de custo, que variam de $\mathrm{R} \$ 5.000$ a $\mathrm{R} \$ 12.000$, durante o período das atividades de formação para que possam se dedicar integralmente à preparação de suas candidaturas, para as quais, a formação oferecida integra diferentes eixos,

\footnotetext{
${ }^{5}$ FOLHA DE SÃO PAULO. Grupo apoiado por Luciano Huck, RenovaBR elege 17 de 120 candidatos: Movimento que prega renovação política tinha lista com 30 nomes de maior potencial. Reportagem de Joelmir Tavares. São Paulo, 08 out. 2018. Disponível em: <https://www1.folha.uol.com.br /poder/2018/10/grupo-apoiado-por-luciano-huck-renovabr-elege-16-de-120-candidatos.shtml>. Acesso em: 08 ago. 2020.

${ }^{6}$ RENOVA BRASIL. O que fazemos. [S. 1.], 08 out. 2018. Disponível em: <https:// renovabr.org/o-que-fazemos/>. Acesso em: 01 ago. 2020.
} 
orbitando em torno de temáticas de campanha, vivência partidária, agendas de políticas públicas, dentre outros ${ }^{7}$.

Contudo, a construção desta interação com a sociedade civil se limita à comunicação de suas ações e educação política da sociedade, sem que haja, contudo, um processo de construção de reivindicações com base no debate e na troca (MOURA, 2019), ou seja, as pautas e posicionamentos do movimento são pré-constituídos, sugerindo uma limitação dialógica que talvez seja similar a dos partidos.

Em 2018, o Movimento lançou 120 candidatos no pleito eleitoral, tendo elegido 17 candidatos, sendo 1 senador, 9 deputados federais e 7 deputados estaduais. Os candidatos eleitos se concentraram principalmente no Partido Novo, com 8 eleitos, depois a Rede Sustentabilidade com 3 eleitos e o restante de eleitos cada um por uma sigla: 1 no PDT, 1 no PPS, 1 no PSL, 2 no PSB e 1 no DEM $^{8}$.

O Renova Brasil apresenta uma visão de representação política técnica e competente atribuída ao representante político, perspectiva cada vez mais frequente nas democracias contemporâneas. $\mathrm{O}$ acesso à elite política cada vez mais é determinado pelo seu nível de educação formal. A ideia de competência e qualificação do representante que o Renova Brasil apresenta em seus enquadramentos também se relaciona com uma imagem de neutralidade que os representantes políticos devem ter, com decisões que devem ser técnicas (MOURA, 2019).

Para Moura (2019), os movimentos de renovação política - como o RenovaBR - se diferenciam em relação a outros movimentos que tiveram proeminência no debate público nos últimos anos, como o Movimento Brasil Livre (MBL), que preponderantemente apresentam reivindicações de contestação/negativas da representação.

\footnotetext{
${ }^{7}$ FOLHA DE SÃO PAULO. Grupo apoiado por Luciano Huck, RenovaBR elege 17 de 120 candidatos: Movimento que prega renovação política tinha lista com 30 nomes de maior potencial. Reportagem de Joelmir Tavares. São Paulo, 08 out. 2018. Disponível em: $<$ https://www1.folha.uol.com.br/poder/2018/10/grupo-apoiado-por-luciano-huck-renovabr-elege-16-de-120-candidatos.shtml>. Acesso em: 08 ago. 2020.

${ }^{8}$ PODER360. Em 1a eleição, movimento RenovaBR elege 16 candidatos: grupo foi fundado em 2017 Promoveu processo seletivo e aulas. [S. 1.], 12 out. 2018. Disponível em: <https://www.poder360.com.br/eleicoes/em-1a-eleicao-movimento-renovabr-elege-16-candidatos/>. Acesso em: 09 ago. 2020.
} 
Surgido a partir do Estudantes pela Liberdade (EPL), ramal do Students for Liberty (SFL) no Brasil, o MBL teve protagonismo nos atos a favor do impeachment de Dilma Rousseff (BAGGIO, 2016). O Students for Liberty, estadunidense, tem vínculos estreitos com o think tank de mesma origem, Atlas Network. O Atlas promove o livre mercado em 95 países9. Ambas as organizações (Students for Liberty e Attas Network) já receberam financiamento de Charles Koch, que, com seu irmão David, controla as indústrias Koch - multinacional estadunidense de energia, combustíveis fósseis e petroquímicos.

Se os - hoje - integrantes do MBL atuassem pelo Estudantes Pela Liberdade, a conexão com o Students for Liberty ficaria explícita (BAGGIO, 2016). No entanto, no site do Atlas Network, há um texto sobre Kim Kataguiri (líder do MBL e deputado federal desde 2018 pelo DEM) e o Movimento Brasil Livre: "Students for Liberty plays strong role in Free Brazil Movement" ". A parceria do Atlas com o think tank brasileiro, o Instituto Millenium, revela seus vínculos com a mídia corporativa brasileira. Entre os patrocinadores do Millenium, Baggio (2016, p. 8-9) cita "os grupos Abril e RBS (filiado à Rede Globo em Santa Catarina e no Rio Grande do Sul)", além de apontar que "o Grupo Estado, que publica o jornal O Estado de S. Paulo, aparecia entre os 'mantenedores e parceiros' do Imil até 2016". Ademais, entre os integrantes da "Câmara de Mantenedores" mostra "João Roberto Marinho (Grupo Globo) e Nelson Sirotsky (Grupo RBS); empresários do setor financeiro [...], além de outros empresários de diferentes setores da economia".

Oportuno comentar sobre as grandes quantias repassadas pelo Atlas e pelo Students for Liberty ao Estudantes pela Liberdade. Em entrevista concedida por Juliano Torres, cofundador do EPL à jornalista Marina Amaral, é possível constatar o fornecimento de cursos de formação política aos membros do MBL: “[...] o Kim é membro da EPL, então ele foi treinado pela EPL também. E boa parte dos organizadores locais são membros do

9 Atlas Network (Estados Unidos). Global Directory. Disponível em: <https://www. Atlasnetwork.org/partners/global-directory>. Acesso em: 05 ago. 2020.

${ }^{10}$ Students for Liberty fazem uma importante jogada no Movimento Brasil Livre. (Tradução livre). Atlas Network (Estados Unidos). Students for Liberty plays strong role in Free Brazil Movement. 2015. Disponível em: < https://www.Atlasnetwork.org/news/article/students-for-liberty-plays-strong-role-in-freebrazil-movement>. Acesso em: 26 jun. 2020. 
EPL. Eles atuam como integrantes do Movimento Brasil Livre, mas foram treinados pela gente, em cursos de liderança"11.

Além dos cursos de formação política oferecidos pelo Students for Liberty por intermédio do EPL ao MBL, houve repasses de grandes quantias entre 2012 e 2016 do SFL ao EPL, e, consequentemente, ao MBL. As despesas do EPL passaram de $\mathrm{R} \$ 29.199,37$, em 2012 para $\mathrm{R} \$ 306.737,05$ em 2016, um crescimento 10 vezes maior no período. Desse montante, mais de 139 mil reais teriam sido bancados pelo Atlas Network, além de R\$ 36.340,00 por parte do Students for Liberty e mais de 150 mil por doadores “confidenciais". Valores esses que se supõe terem sido repassados do Estudantes pela Liberdade ao MBL para utilização na campanha a favor do impeachment da presidenta Dilma, realizada entre 2015 e 2017. Curiosamente, o MBL foi retirado da lista de parceiros do Atlas pouco antes do impeachment de Rousseff (BAGGIO, 2016).

Tratando-se especificamente do sistema político-partidário, o MBL tem obtido protagonismo nos processos eleitorais desde 2016. Em 2018, o desempenho foi bastante expressivo. No Senado, foram eleitos Marcos Rogério (DEM-RO) e Eduardo Girão (Pros-CE) e, na Câmara, Kim Kataguiri (DEM-SP), Zé Mário (DEM-GO), Jerônimo Goergen (PP-RS) e Sóstenes Cavalcante (DEM-RJ). Além disso, três coordenadores na linha de frente do MBL tornaram-se políticos de ofício, todos pelo DEM: Fernando Holiday foi eleito vereador de São Paulo em 2016, e em outubro conquistou mandato, além de Kim, como já mencionado, Arthur do Val "Mamãe Falei" (DEM) ${ }^{12}$.

Embora se reconheça a importância destes movimentos para a oxigenação do debate público e para o regime democrático, é imperativo verificar, por outro lado, quais são os efeitos e eventuais desequilíbrios que eles podem provocar no sistema eleitoral brasileiro, tendo em vista que aos

${ }^{11}$ AGÊNCIA PÚBLICA. A nova roupa da direita: Rede de think tanks conservadores dos EUA financia jovens latino-americanos para combater governos de esquerda da Venezuela ao Brasil e defender velhas bandeiras com um nova linguagem. Reportagem de Marina Amaral. 23 jun. 2015. Disponível em: <https://apublica.org/2015/06/a-nova-roupa-da-direita/>. Acesso em: 24 ago. 2020.

12 FOLHA DE SÃO PAULO. Após eleger uma 'bancada', MBL rediscute atuação e cogita partido: Movimento que ganhou visibilidade no impeachment de Dilma contabiliza 4 deputados e 2 senadores eleitos. Anna Virginia Balloussier. [S. 1.], 23 jun. 2015. Disponível em: < https://www1.folha.uol.com.br/poder/2018/11/apos-eleger-uma-bancada-mbl-rediscute-atuacao-e-cogita-partido.shtml>. Acesso em: 24 ago. 2020.

Resenha Eleitoral (Florianópolis), v. 24, n. 2, p. 15-42, 2020 
partidos se impõe um regime jurídico de Direito Público, que não se aplica a estes movimentos - não obstante ambos sejam pessoas jurídicas de direito privado.

Esse é um fator que parece somar-se à crise do sistema político-partidário no enfraquecimento dos partidos, uma vez que para eles se aplica uma série de óbices legais em diversas matérias.

De forma resumida, é importante relembrar que, por dicção constitucional expressa, os partidos políticos submetem suas contas à apreciação da Justiça Eleitoral em processo de natureza judicial. Além disso, teleologicamente as legendas existem para "assegurar, no interesse do regime democrático, a autenticidade do sistema representativo e defender os direitos fundamentais definidos na Constituição Federal""13. Assim, pela centralidade na realização do sistema democrático representativo, os partidos políticos estão submetidos a uma série de regras que vão desde sua criação, passando pelo funcionamento interno, até àquelas relacionadas com o processo eleitoral.

O caso dos cursos promovidos pelo MBL junto ao Students for Liberty, assim como as bolsas concedidas pelo RenovaBR, serve de alerta para as possibilidades de fatores alheios às regras de financiamento e prestação de contas desequilibrarem a disputa eleitoral. A presença dos movimentos como players do processo eleitoral acaba gerando uma disputa na qual os participantes estão submetidos a regramentos distintos. É nessa desigualdade que reside um desvio dos movimentos ao controle estatal, vez que sobre eles não recai o peso do regime jurídico imposto às legendas partidárias. Cabe frisar que a legislação sobre o tema é extensa e há numerosos pontos sobre os quais há alguma forma de regulação.

Rubens Beçak, professor da Universidade de São Paulo (USP), aponta que esses movimentos "podem estar oferecendo determinados benefícios aqui e ali que outros candidatos não beneficiados por esses fundos não teriam condições de arcar"14, especialmente diante das rígidas regras

${ }^{13}$ BRASIL. Lei $\mathbf{n}^{\mathbf{0}} \mathbf{9 0 9 6}$, de 19 setembro de 1995. Dispõe sobre partidos políticos, regulamenta os arts. 17 e 14, $\int 3^{\circ}$, inciso V, da Constituição Federal. Brasília, 20 set. 1995. Disponível em: <http://www.planalto.gov.br/ccivil_03/leis/19096compilado.htm\#: :text $=$ Art.,fundamentais $\% 20$ definidos $\% 20$ na $\% 20$ Constitui $\%$ C3 $\%$ A $7 \%$ C3 $\%$ A $30 \% 20 \mathrm{Fe}-$ deral>. Acesso em: 17 jun. 2020.

${ }^{14}$ ESTADO DE S. PAULO. Em busca de renovação, grupos buscam partidos para candidaturas cívicas em 2018. Reportagem de Jonathas Cotrim. Brasil, 22 nov. 2017. 
de financiamento eleitoral e de prestação de contas a que se submetem os partidos. Esse risco se mostra evidente diante de estudos que indicam a preponderância do financiamento como fator de influência no resultado das eleições (SILVA, 2020).

Com o julgamento da Ação Direta de Inconstitucionalidade (ADI) n. 4.650, que proibiu o financiamento eleitoral por empresas e/ou pessoa jurídica, os partidos passaram a buscar doações com pessoas físicas. No entanto, essa não parece ser a forma mais eficiente de levantar recursos, em razão da pouca credibilidade que possuem. Para eles, importa muito mais o Fundo Especial de Financiamento de Campanhas (FEFC), que, todavia, vem comprimindo a igualdade e a democracia interna das legendas, na medida em que o dinheiro fica concentrado com os líderes partidários.

Por sua vez, os movimentos, diferentemente dos partidos, conseguem arrecadar valores vultosos mediante doações de pessoas físicas. A boa credibilidade que ostentam, se comparado aos partidos, poderia ser a principal razão para explicar esta diferença. No entanto, a partir do caso Tabata Amaral é possível constatar a existência de outros fatores que interferem na obtenção de recursos por doações de pessoas físicas. Antes cumpre lembrar que a reforma eleitoral de 2017 limita o valor da doação de pessoas físicas às candidaturas ao total de $10 \%$ da renda bruta anual declarada à Receita Federal, enquanto o autofinanciamento ficou limitado a 10\% do limite de gastos da campanha.

Esse enquadramento jurídico acaba possibilitando doações de valores extremamente altos. É o caso, por exemplo, da campanha eleitoral da deputada federal Tabata Amaral, membro do RenovaBR. Segundo informações do site DivulgaCandContas, do Tribunal Superior Eleitoral, em 2018, Patrice Philippe Nogueira Baptista Etlin doou R \$90.000,00 para a campanha de Tabata. Veja-se que a contribuição de um único doador é quase o mesmo valor do total repassado pela Direção Nacional do PDT à parlamentar - que foi de R \$ 100 mil, proveniente do Fundo Eleitoral. Além disso, outros oito doadores realizaram transferência de recursos em valores acima dos $\mathrm{R} \$ 50.000,00$. Tabata recebeu um total de $\mathrm{R} \$ 509,5$ mil em doa-

Disponível em: <https://infograficos.estadao.com.br/focas/politico-em-construcao/ materia/em-busca-de-renovacaogrupos-buscam-partidos-para-candidaturas-civicas-em-2018>. Acesso em: 04 jul. 2020. 
ções de pessoas físicas, dos quais apenas $\mathrm{R} \$ 58,1$ mil foram arrecadados por financiamento coletivo ${ }^{15}$.

Portanto, o principal fator responsável pela diferença no recebimento de doações de pessoas físicas não está na credibilidade dos movimentos, mas na relação de proximidade que eles possuem com grandes empresários, que no caso do Renova Brasil são fundadores e mantenedores, e em relação ao MBL são responsáveis pelo repasse de grandes quantias nos últimos anos. Veja-se que, embora esteja proibido o financiamento de campanha por pessoas jurídicas, na prática, algumas pessoas físicas aproveitam-se de lacunas legais para fazerem doações de valores cujo montante é similar à capacidade financeira de empresas. Somado a isso, há o financiamento de bolsas de formação de lideranças e atividades objetivando futuras candidaturas, sugerindo uma forma de financiamento antecipado de campanha.

Esse fato colabora para a percepção de que há uma tentativa de escape dessas organizações do regime jurídico imposto aos partidos, que são proibidos de usar capital estrangeiro, regulamento que não se aplica aos movimentos - que recebem financiamento de fora do país para realização de suas atividades na formação e promoção de seus quadros. A reivindicação das candidaturas avulsas representaria a maior amostra da tentativa de fuga ou burla de tais regras.

Além disso, a Justiça Eleitoral já precisou intervir em campanhas promovidas por esses movimentos, como ocorreu com o MBL, condenado por realizar propaganda eleitoral de um de seus integrantes em $2016^{16}$. Essa situação alerta para o fato de que as instituições que recebem aporte de diversos empresários têm o potencial de promover a imagem de seus integrantes de forma expressiva, promovendo uma espécie de campanha.

O suporte financeiro concedido por esses novos movimentos a seus integrantes desperta para outra situação: os constantes casos de parlamentares que agem contra a orientação de suas siglas em situações de votações, articulações etc. Alguns exemplos: o caso de Arthur do Val "Mamãe

\footnotetext{
${ }^{15}$ Modalidade de doação em plataformas on-line previamente autorizadas pelo Tribunal Superior Eleitoral. As doações acima de R \$ 1.064,10 devem ser feitas via transferência bancária.

${ }^{16}$ CONSULTOR JURÍDICO. Justiça Eleitoral condena MBL e Fernando Holiday por propaganda ilegal. Reportagem de Sérgio Rodas. Brasil, 20 jan. 2015. Disponível em: <https://www.conjur.com.br/2018-jan-20/juiz-eleitoral-condena-mbl-fernando-holiday-propaganda-ilegal $>$. Acesso em: 25 maio 2020.
} 
Falei”, expulso do Democratas por agir em contrariedade ao partido por diversas vezes ${ }^{17}$, e o emblemático caso dos deputados que votaram contra seus partidos na Reforma da Previdência ${ }^{18}$.

Conforme a Lei no 9.096/1995, o estatuto do partido poderá estabelecer medidas disciplinares básicas e normas sobre penalidades "ao parlamentar que se opuser, pela atitude ou pelo voto, às diretrizes legitimamente estabelecidas pelos órgãos partidários". No entanto, a regulamentação estatutária não tem contemplado muitas divergências ocorridas na relação de partidos e candidaturas, especialmente nos recentes casos de interação entre movimentos suprapartidários e partidos políticos. Além disso, o princípio da liberdade para o exercício do mandato é outro princípio constitucional eleitoral que impõe o reconhecimento "da vedação ao mandato imperativo, de caráter predominantemente privado e que não encontra espaço nas constituições ocidentais democráticas contemporâneas". Não seria possível então vincular o candidato eleito a disposições do eleitorado ou do partido (SALGADO, 2011, p. 113).

Diante da votação de integrantes desses movimentos em acordo com o posicionamento de seus líderes e em desacordo com seus partidos, questiona-se se isso não tem sido uma forma de burlar todas as regras a que estão submetidos os partidos para garantir a eleição de seus candidatos por meio do poder econômico e, utilizar o espaço destes partidos para defender políticas e programas diferentes daqueles promovidos por instituições pelas quais esses parlamentares se candidataram e se elegeram.

\section{Um museu de grandes novidades: a história se repete, mas a força deixa a história mal contada}

Para além das questões que se colocam em face de uma aparente fuga do regime jurídico imposto aos partidos políticos, uma outra característica desses atores chama a atenção. A partir da análise dos novos movimentos e da atuação do MBL e do RenovaBR, constatou-se similaridades

${ }^{17}$ FOLHA DE SÃO PAULO. DEM expulsa Arthur Mamãe Falei, pré-candidato do MBL à Prefeitura de São Paulo. Reportagem de Carolina Linhares. São Paulo, nov. 2019. Disponível em: <https://bit.ly/2AQ3gKV>. Acesso em: 03 jul. 2020.

${ }^{18}$ O GLOBO. Votação da reforma da Previdência expõe atritos entre partidos e movimentos de renovação. Reportagem de Miguel Caballero. Brasil, 12 jul. 2019. Disponível em: <https://oglobo.globo.com/brasil/votacao-da-reforma-da-previdencia-expoe-atritos-entre-partidos-movimentos-de-renovacao-23801747>.Acesso em: 04 jun. 2020.

Resenha Eleitoral (Florianópolis), v. 24, n. 2, p. 15-42, 2020 
com um período histórico no qual houve intervenção de elementos externos ao sistema político-partidário no processo eleitoral e na democracia representativa (RÀMIREZ, 2019).

Barros e Wanderley (2019) narram que a experiência populista brasileira ocorreu em outra época, mas contava com forças paralelas àquelas que vemos operando hoje. Dessa forma, buscando traçar um paralelo apto a apresentar respostas para as questões enfrentadas, analisou-se a atuação de um complexo político-militar que agiu por meio de organizações multipartidárias em conexão com instituições think tank no processo que levou à quebra de regime ocorrida em 1964 com o golpe militar: o complexo IPES/IBAD .

De acordo com Dreifuss (1981, p. 71), no início da década de 1960, articulado pela política desenvolvimentista de Juscelino Kubitschek, o Brasil passava por uma intensificação interna dos interesses multinacionais e associados, tornando-se esses interesses a força socioeconômica dominante. $\mathrm{O}$ processo foi acompanhado pela formação de um aparelho civil e militar modernizante, composto por um novo conjunto de agentes, com atribuição sobre os temas "relativos à produção e administração política do bloco econômico multinacional e associado". Esses agentes - nominados "modernizante-conservadores" - eram verdadeiros intelectuais orgânicos ${ }^{19}$.

Essa rede de companhias multinacionais que proporcionou o crescimento dos interesses socioeconômicos do setor empresarial no Brasil, formava uma espécie de sistema nervoso central da ordem econômica do planeta. Esses interesses obtiveram apoio dos próprios governos de origem dessas multinacionais. Estabeleceu-se assim, uma liderança global de empresários, de modo que a burguesia do país, formada pelas elites locais, conectadas organicamente pelos interesses em comum e pela atuação econômico-política - fazia parte de uma burguesia internacional, preocupada

${ }^{19}$ Gramsci assevera que esses "intelectuais orgânicos" têm uma ligação vital com a classe que lhes deu origem. Seu modo de agir não consiste "na eloquência, motor exterior e momentâneo dos afetos e das paixões, mas num imiscuir-se ativamente na vida prática", numa relação orgânica com a classe que lhes deu origem, garantindo a essa um consenso social a respeito do seu domínio e promovendo seu pleno desenvolvimento. "Uma das mais marcantes características de todo grupo social que se desenvolve no sentido do domínio é sua luta pela assimilação e pela conquista 'ideológica' dos intelectuais tradicionais, assimilação e conquista que são tão mais rápidas e eficazes quanto mais o grupo em questão elaborar simultaneamente seus próprios intelectuais orgânicos.” GRAMSCI, Antonio. Intelectuais e a Organização da Cultura. Rio de Janeiro: Civilização Brasileira, p. 4-9, 1968. 
com crescimento próprio, não com o fortalecimento de uma independência nacional (DREIFUSS, 1981).

Os interesses multinacionais e associados tinham forte representação na estrutura dos think tanks "técnicos" do início da década de 1960. Nesse cenário, o bloco multinacional e associado publicizava seus interesses e trabalhava num enfraquecimento do caráter corporativista associativo e de regime populista do sistema, buscando as mudanças sociais que sua classe demandava, passando por três estruturas políticas distintas: (i) escritórios de consultoria tecno-empresarial; (ii) associações de classe empresariais renovadas; (iii) grupos de ação expressando interesses empresariais e modernizante-conservadores, sendo o Instituto Brasileiro de Ação Democrática - IBAD o mais importante deles (DREIFUSS, 1981).

Criado em 1959, quando representantes das classes empresariais e de grupos conservadores comunicaram ao recém-eleito governador da Guanabara sobre a organização das forças econômicas do país "para promover a defesa da democracia, das instituições e do regime", o - em tese, think tank - Instituto Brasileiro de Ação Democrática (IBAD) sofreu denúncias de ser a principal base da CIA, agência de inteligência civil do governo dos Estados Unidos, no Rio de Janeiro, caracterizado então como uma organização anticomunista. Foi por meio do IBAD que os intelectuais orgânicos das classes empresariais estabeleceram ligações com "empresários, militares e detentores de altos cargos públicos”, e atuaram na mobilização do público em geral (DREIFUSS, 1981, p. 101-102).

Com a crise política que surgia à época e a percepção da pequena adesão popular aos projetos políticos dos setores dominantes, articulou-se um plano para alterar as condições, sendo o Instituto de Pesquisas e Estudos Sociais (IPES), idealizado para esse fim por empresários alinhados com políticos, tecnocratas, militares, membros do clero e outros segmentos de menor relevância (RAMIREZ, 2019). Segundo Dreifuss (1981), a renúncia de Jânio Quadros (que havia obtido apoio do IBAD nas eleições de 1960), em agosto de 1961, frustrou o projeto apoiado pelo bloco de interesses multinacionais e associados (especialmente em razão de seu vice, João Goulart, que assumiu a presidência, compor o grupo nacional-reformista). Desse modo, visando à promoção de um combate às políticas governistas e promover um modelo que propiciasse o desenvolvimento capitalista, decidiu-se por ativar o IPES, surgido no fim do governo de Jânio Quadros, com a reunião de figuras de São Paulo e do Rio de Janeiro. 
O IBAD funcionava como um "canal financeiro de fundos multinacionais para o IPES". Entre as empresas nacionais e estrangeiras que financiavam a rede IBAD/ADEP/Promotion S. A. (rede controlada pelo IBAD), o autor aponta a Texaco, a Shell, a Coca-Cola, a Cia. de Cigarros Souza Cruz, a General Motors etc. "Por intermédio de seus especializados grupos de ação e usando todos os meios disponíveis, o complexo IPES/ IBAD conseguia estabelecer a presença política, ideológica e militar do bloco multinacional e associado em toda área de disputa" (DREIFUSS, 1981).

Taticamente, o complexo IPES/IBAD estava engajado em uma campanha que visava causar um impacto ideológico (em especial na classe média) e no aparelho do Estado, com participação da grande mídia. Cabe mencionar a pressão ideológica por meio de ligações com os maiores veículos (Grupo Globo, Record, F. de São Paulo, O Estado de São Paulo), na produção de séries, curtas-metragens, folhetos, cartilhas, inclusive com disputa das mídias menores, com propósito específico, valendo-se de uma espécie de fake news da época. Além disso, o complexo lidava com a formação política e ideológica, cooptação e mobilização de ativistas sindicais, líderes camponeses e militantes rurais, estudantes e líderes militares (DREIFUSS, 1981).

Conforme Ramirez (2019), a seccional paulista do IPES formalizou convênio com a Sociedade de Estudos Interamericanos, com participação de 350 militantes por ano, além da existência da Escola de Líderes Operários - para a formação dos indivíduos que atuariam nessas áreas de acordo com as diretrizes do Instituto.

O bloco de interesses multinacionais e associados tinha por objetivo intervir nas decisões políticas bloqueando as políticas reformistas do governo e do bloco trabalhista de esquerda no Congresso, buscando isolar o Executivo e privá-lo do apoio da classe média. Desse modo, o complexo IPES/IBAD agia no Congresso e nos partidos, especialmente, por meio da Ação Democrática Parlamentar (ADP), "bloco multipartidário de senadores e deputados federais conservadores e reacionários, a maior parte da UDN e do PSD, organizados em todo o país em uma rede formada por grupos da Ação Democrática Popular (ADEP)" (DREIFUSS, 1981, p. 321 322). Para Ramirez (2019), pode-se identificar, ao longo desse processo, uma clara distribuição de tarefas de acordo com a área de incumbência de cada setor envolvido, voltada para a construção de um projeto de refundação de sociedade. 
Nas eleições de 1962, o complexo patrocinou candidatos, que eram compelidos a prometer sua lealdade ao IBAD acima da lealdade ao seu partido. Quando os eleitores foram às urnas, mais de um terço da Câmara dos Deputados veio a ser beneficiado pelo apoio da rede IPES/ IBAD/ADEP: 250 candidatos foram eleitos a deputado federal, 600 a deputado estadual, 8 a governos estaduais e vários senadores, prefeitos e vereadores (DREIFUSS, 1981).

Uma Comissão Parlamentar de Inquérito foi instaurada em 1963 para averiguar as atividades e fontes de fundos da rede IPES/IBAD/ADEP e também, investigar as alegadas irregularidades nas eleições de 1962. Entretanto, desde o início, a CPI mostrava irregularidades (formada majoritariamente por beneficiários do apoio - pelo menos cinco de seus nove membros haviam sido favorecidos por esses fundos secretos) (DREIFUSS, 1981) e, a despeito das fontes financeiras comuns, da participação simultânea de membros em ambas organizações e da ação conjunta, fracassou em estabelecer ligações entre o IBAD e o IPES. As investigações revelaram apenas a responsabilidade do IBAD no processo de corrupção eleitoral, ocasionando o encerramento de suas atividades.

O golpe de Estado ocorrido no Brasil em 1964 resultou de um processo político de longa duração, no qual as normas reguladoras do ambiente democrático passaram a não mais dar conta dos conflitos, situação que também se expressou nas esferas econômica e social. O embate assim transcendia o campo das ideias, tratando-se de uma disputa referente aos aspectos estruturais da sociedade que se expressava ideologicamente. $\mathrm{O}$ objetivo, como visto, era a promoção ideológica de interesses multinacionais e associados aliada à execução no Congresso e na política de âmbito estadual por meio de braços políticos como a ADP.

Para Barros e Wanderley (2019, p. 400), “o compromisso assumido pelo IPES em restabelecer os valores da classe média brasileira no início na década de 1960 é semelhante aos eventos populistas contemporâneos no Brasil e no mundo anglo-saxão". Essas similaridades com as conexões atuais entre entidades de promoção ideológica e de ação política, mostram a necessidade de analisar os discursos promovidos por essas instituições a fim de constatar se há também similaridade nas ideias e princípios por elas veiculados. Levando sempre em conta, claro, a distância temporal entre os períodos para não cair em leituras anacrônicas, é importante analisar quais as propostas políticas e a ideologia defendidas em ambos os momentos, com o objetivo de identificar paralelos e, em caso de positiva, estabelecer perspectivas. 
Para essa análise, e considerando o recorte proposto, realizou-se uma comparação entre os documentos veiculados pelos movimentos MBL, RenovaBR, Instituto Millenium (think tank que está conectado ao Atlas Network, ao qual o MBL também esteve até 2016) e pelo IPES, a fim de confrontar não só as ideias promovidas pelas instituições envolvidas no processo atual, mas também, dessas com uma instituição que esteve envolvida no processo de intervenção política que levou a tomada do Estado por um bloco multinacional e associado em 1964.

Passando à comparação, denota-se dos documentos veiculados por essas instituições uma tendência a declarar afastamento da política partidária. O RenovaBR se preocupa em apontar expressamente em sua página que não é um partido nem um movimento político ${ }^{20}$. Já o MBL surgiu declarando-se apartidário, buscando colocar-se como alternativa ao sistema, posicionamento que mudou ao longo dos anos - atualmente o movimento tem buscado se institucionalizar ${ }^{21}$. O Instituto Millenium se declara como "entidade sem fins lucrativos e sem vinculação político-partidária"22, enquanto o IPES se identificava como "entidade apolítica"23.

Nesse mesmo sentido está o posicionamento dessas instituições acerca da corrupção no país, apontada como problema central da nação e forte argumento na construção de uma ideia antissistema tradicional. $\mathrm{O}$ RenovaBR apregoa a honestidade entre seus valores, defendendo o fim da corrupção, dos desvios de conduta e de políticos que trabalham em benefício próprio ${ }^{24}$. Desde o seu surgimento, o MBL encampou uma grande campanha de mobilização contra o PT e contra o próprio sistema político, sendo comum mencionar a existência de "movimentos pró-corrupção"25.

${ }^{20}$ RENOVA BRASIL. Quem Somos? 2018. Disponível em: <https://renovabr.org/o-que-fazemos/> Acesso em: 02 jul. 2020.

${ }^{21}$ EL PAÍS. A segunda metamorfose do MBL para seguir influente no Brasil de Bolsonaro. Reportagem de Felipe Betim. São Paulo, 05 dez. 2018. Disponível em: <https:// brasil.elpais.com/brasil/2018/12/03/politica/1543850784_783436.html>. Acesso em: 07 ago. 2020.

22 INSTITUTO MILLENIUM. Quem Somos. Disponível em: < https://www.institutomillenium.org.br/institucional/quem-somos/>. Acesso em: 22 jul. 2020.

23 23INSTITUTO DE PESQUISAS E ESTUDOS SOCIAIS. O que é o IPES?. Rio de Janeiro, 1961. Disponível em: <https:/ / bit.ly/2ClY3uF>. Acesso em: 02 jul. 2020.

${ }^{24}$ RENOVA BRASIL. O que fazemos. [S. 1.], 08 out. 2018. Disponível em: <https:// renovabr.org/o-que-fazemos/>. Acesso em: 01 ago. 2020.

${ }^{25}$ MOVIMENTO BRASIL LIVRE. Movimento pró-corrupção perde força: impeachment está mais perto! 2020. Facebook: MBL. Disponível em: <https://www.facebook. 
Quanto aos think tanks, o Instituto Millenium aborda essa questão constantemente, sendo possível encontrar em seu site uma "etiqueta" voltada apenas para este tema, na qual vários textos de opinião abordam questões como impunidade, eficiência na gestão e o combate à corrupção no país como, por exemplo, a grande vitória do processo que culminou no impeachment de Dilma Rousseff, em 2016 26. Já o IPES divulgava boletins mensais em que tratava do assunto. Em um deles, constata-se menção ao manifesto à nação divulgado por um engenheiro paulista, que asseverava: "Nada se faz para coibir a sarabanda infernal da política vigente, a odiosa distribuição de favores e privilégios, a indisciplina generalizada, a demagogia desenfreada e o avanço de uma corrupção sem limites" ${ }^{27}$. Dessa forma, o estabelecimento de uma relação entre o sistema político e a ideia de corrupção também é um ponto de conexão entre as instituições.

Para o restante da análise, imprescindível comentar que o RenovaBR apresenta um discurso de proposição de soluções e de mobilização, o que demonstra que o discurso de desconfiança, contrariedade às instituições políticas e aos representantes têm papel marginal em suas narrativas. Trata-se de reconhecer que o RenovaBR inclui-se no chamado Movimento de Renovação Política, ainda que ele próprio não reconheça ao se apresentar nas plataformas virtuais, com narrativas relacionadas à representação eleitoral, seguindo suas táticas de pautar agendas de políticas públicas e ter candidatos eleitos, enquanto que o IPES, o Millenium e o MBL possuíram/ possuem uma atuação voltada, em maior ou menor medida, à construção de um novo imaginário social ou para a alteração do senso comum.

Em relação ao restante das instituições analisadas (MBL, Instituto Millenium e IPES), a defesa do livre mercado e da iniciativa privada e pela abertura ao capital estrangeiro também são pontos comuns entre os conteúdos veiculado pelas instituições em tela ${ }^{28}$. Por fim, as três instituições que

com/mblivre/posts/357430421047774/>. Acesso em: 23 jul. 2020.

${ }^{26}$ INSTITUTO MILLENIUM. Etiqueta - Corrupção. Disponível em: < https://www. institutomillenium.org.br/etiqueta/corrupcao/?a1=60>. Acesso em: 22 jul. 2020.

${ }^{27}$ INSTITUTO DE PESQUISAS E ESTUDOS SOCIAIS. Boletim Mensal. Ano 2, n. 7 , fevereiro 1963, n. avulso. Disponível em: <http://sian.an.gov.br/sianex/consulta/Pesquisa_Livre_Painel_Resultado.asp?v_Cod Referencia_id=118 6630\&v_aba=1>. Acesso em: 02 jul. 2020.

${ }^{28}$ MOVIMENTO BRASIL LIVRE. Propostas aprovadas no Primeiro Congresso nacional do Movimento Brasil Livre. São Paulo, nov. 2015. Disponível em: <https:// mbl.org.br/wordpress/wpcontent/uploads/2017/05/propostas-mbl.pdf $>$. Acesso em: 
seguem como objeto de análise promoveram ou promovem ideias anticomunistas. O MBL possui diversas manifestações em relação ao tema, sempre de teor pejorativo e criminalizante ${ }^{29}$. Já o Millenium possui também para este ponto uma 'etiqueta' em seu site, na qual é possível localizar diversos textos promovendo ideias anticomunistas ${ }^{30}$, assim como o IPES, que distribuía várias obras de propaganda anticomunista, dentre elas: "Como os Vermelhos Preparam uma Arruaça", de Eugene H, Metherin, conforme documentos presentes no sítio do Arquivo Nacional relacionados ao think tank ${ }^{31}$.

Comprova-se assim, uma proximidade não só na organização e nas conexões estabelecidas pelas instituições envolvidas em ambos os períodos, mas também entre os projetos por elas promovidos. Essa similaridade e o processo que levou ao golpe militar de 1964 apontam para os riscos da falta de regulação de elementos externos alheios à política institucionalizada. Dado que, os novos movimentos apropriam-se do discurso antipartidário para formar quadros enquanto utilizam o espaço dos partidos para promovê-los dentro do sistema eleitoral, o que tem gerado contradições, como o caso de parlamentares que têm votado contra os seus partidos. Além disso, esses movimentos não possuem amarras às fontes de financiamento, o que abre margem para um desequilíbrio no processo, dado o peso que o financiamento tem no resultado das eleições.

06/07/2020; INSTITUTO MILLENIUM. Carta de Princípios. Disponível em: < https://www.institutomillenium.org.br/institucional/carta-de-principios/>. Acesso em: 22 jul. 2020; INSTITUTO MILLENIUM. Etiqueta - Investimento Estrangeiro. Disponível em: <https://www.institutomillenium.org.br/etiqueta/investimento-estrangeiro/>. Acesso em: 22 jul. 2020; INSTITUTO DE PESQUISAS E ESTUDOS SOCIAIS. O que é o IPES? Rio de Janeiro, 1961. Disponível em: < https://bit.ly/2ClY3uF>. Acesso em: 02 jul. 2020 .

${ }^{29}$ MOVIMENTO BRASIL LIVRE. 100 anos de comunismo: pessoas preferem ir em uma missão quase suicida do que ficar mais um dia sob o regime. 2020. Facebook: MBL. Disponível em: <https://www.facebook.com/mblivre/photos/100-anos-de-comunismo-pessoas-preferem-ir-em-umamiss\%C3 \%A3o-quase-suicida-do-que-fic/740391226085023/>. Acesso em: 09 jul. 2020.

${ }^{30}$ INSTITUTO MILLENIUM. Etiqueta - Comunismo. Disponível em: < https:/ /www. institutomillenium.org.br/etiqueta/comunismo/>. Acesso em: 22 jul. 2020.

31 INSTITUTO DE PESQUISAS E ESTUDOS SOCIAIS. Livros distribuídos pelo IPES. Disponível em: <http://sian.an.gov.br/sianex/consulta/resultado_pesquisa_new. asp? ${ }_{\text {v_pesquisa }}=$ comunismo\&v_fundo_colecao=>. Acesso em: 02 jul. 2020. 


\section{Considerações finais: ainda somos os mesmos e vivemos como nossos pais?}

Na política, muito se inventa para que tudo fique como está - se levanta muita poeira sem mexer a areia. $\mathrm{O}$ surgimento (ou melhor, ressurgimento) dos movimentos políticos parece confirmar essa visão. Não há nada de novo no ar: tudo ficou no lugar, os mesmos interesses, os mesmos discursos, agora travestidos com novos rótulos, novas estampas, nomes inspiradores.

Pode ser que seja uma visão limitada, e que de fato o novo no Brasil nunca seja levado a sério. No entanto, não apenas as coincidências com os movimentos atuantes quando da ruptura constitucional estão presentes: os discursos de ruptura com uma política que se vê como corrompida muitas vezes, servem apenas para escapar do sistema de controle sobre os partidos políticos, principalmente em termos de financiamento.

Para que a disputa política seja de fato mais competitiva, é preciso alterar a distribuição de recursos diretos e indiretos para os partidos políticos, regular sua alocação nos órgãos estaduais e municipais, incluir dispositivos sobre democracia interna nas agremiações partidárias e desenvolver instrumentos de proteção jurídica dos direitos fundamentais de pessoas filiadas. Até que uma emenda à Constituição venha a retirar a exclusividade dos partidos na apresentação de candidaturas, é forçoso reconhecer que os partidos são os protagonistas na arena eleitoral e que, segundo mutação (in) constitucional do Supremo Tribunal Federal (STF), titularizam os mandatos parlamentares.

Para que os movimentos políticos possam entrar nesta seara, é necessária uma reforma que os incorporem como atores eleitorais, com garantias e restrições equivalentes a dos demais participantes. Sua atuação livre, sem as conformações impostas aos partidos, faz com que haja menos equilíbrio na disputa e menos controle sobre a atuação dos próprios movimentos e de parlamentares a eles vinculadas.

Por fim, como desde há muito se considera definitiva a relação entre dinheiro e sucesso eleitoral, é indispensável aplicar as regras de financiamento de candidaturas às alternativas construídas pelos movimentos, bem como verificar a origem de seus recursos para garantir sua observância aos limites constitucionais. É preciso assegurar transparência - afinal, depois dos desdobramentos das tais “jornadas", uma das questões mais urgentes é: quem paga para a gente ficar assim? 


\section{Referências}

AGÊNCIA PÚBLICA. A nova roupa da direita: Rede de think tanks conservadores dos EUA financia jovens latino-americanos para combater governos de esquerda da Venezuela ao Brasil e defender velhas bandeiras com um nova linguagem. Reportagem de Marina Amaral. 23 jun. 2015. Disponível em: <https://apublica.org/2015/06/a-nova-roupa-da-direita/>. Acesso em: 24 ago. 2020.

ATLAS NETWORK (Estados Unidos). Global Directory. Disponível em: $<$ https://www.atlasnetwork.org/partners/global-directory>. Acesso em: 05 ago. 2020.

ATLAS NETWORK (Estados Unidos). Partners - America Latina e Caribe: Brasil. Disponível em: <https://www.atlasnetwork.org/partners/global-directory/latin-america-and-caribbean/brazil>. Acesso em: 04 ago. 2020.

ATLAS NETWORK (Estados Unidos). Students for Liberty plays strong role in Free Brazil Movement. 2015. Disponível em: <https://www.atlasnetwork.org/news/ article/ students-for-liberty-plays-strong-role-in-free-brazil-movement>. Acesso em: 26 jun. 2020.

AVRITZER, Leonardo. Participation in democratic Brazil: from popular hegemony and innovation to middle-class protest. Campinas: Opinião Pública, v. 23, n. 1, 2017. Quadrimestral.

BAGGIO, Kátia Gerab. Conexões ultraliberais nas Américas: o think tank norte- americano Atlas Network e suas vinculações com organizações latino-americanas. Anais do XII encontro internacional da ANPHLAC, 2016, Campo Grande - MS. ANPHLAC, 2016. Disponível em: <https://www.ifg.edu.br/ attachments/article $/ 7536 /$ Conex $\% \mathrm{C} 3 \% \mathrm{~B} 5 \mathrm{es} \% 20$ ultraliberais $\% 20$ nas $\% 20$ Am $\%$ C3\%A9ricas $\% 20 \% \% 20$ think $\% 20$ tank $\% 20$ norte-americano $\% 20$ Atlas $\% 20$ Network $\% 20$ e $\% 20$ suas $\% 20$ vincula $\%$ C3 $\%$ A $7 \%$ C3\%B5es $\% 20$ com $\% 20$ organiza $\%$ C 3\%A7\%C3\%B5es $\% 20$ latino-americanas $\% 20 \% \mathrm{E} 2 \% 80 \% 93 \% 20$ K\%C3\%A1tia\%20Baggio. pdf>. Acesso em: 04 ago. 2020.

BARROS, Amon; WANDERLEY, Sérgio. Brazilian businessmen movements: Right-wing populism and the (dis)connection between policy and politics. São Paulo, Organization, 2019.

CAVALCANTI, Davi Barboza. Quem são os grupos de direita que ganharam as ruas do país: uma análise de redes com ênfase nos atores e nas pautas do Movimento Brasil Livre e do Vem pra Rua. 2019. 106 f. Tese (Doutorado) Curso de Ciência Política, Universidade Federal de Pernambuco, Recife, 2019. 


\section{CONSULTOR JURÍDICO. Justiça Eleitoral condena MBL e Fernando} Holiday por propaganda ilegal. Reportagem de Sérgio Rodas. Brasil, 20 jan. 2015. Disponível em: <https://www.conjur.com.br/2018-jan-20/juiz-eleitoral-condena-mbl-fernando-holiday-propaganda-ilegal>. Acesso em: 25 maio 2020.

CORPORACIÓN LATINO BARÓMETRO. Relatório do Latinobarômetro 2018. Santiago, Chile, 2018. Disponível em: <https://www.latinobarometro. org/lat.jsp>. Acesso em: 19 jul. 2020.

DREIFUSS, René Armand. A conquista do Estado: ação política, poder e golpe de classe. Petrópolis, Vozes, v. 3, 1981.

\section{EL PAÍS. A segunda metamorfose do MBL para seguir influente no}

Brasil de Bolsonaro. Reportagem de Felipe Betim. São Paulo, 05 dez. 2018. Disponível em: <https://brasil.elpais.com/brasil/2018/12/03/politica/1543850784_783436.html>. Acesso em: 07 ago. 2020.

ESTADO DE S. PAULO. Em busca de renovação, grupos buscam partidos para candidaturas cívicas em 2018. Reportagem de Jonathas Cotrim. Brasil, 22 nov. 2017. Disponível em: <https://infograficos.estadao.com.br/ focas/politico-em-construcao/materia/ em-busca-de-renovacao-grupos-buscam-partidos-para-candidaturas-civicas-em-2018>. Acesso em: 04 jul. 2020.

FOLHA DE SÃO PAULO. Após eleger uma 'bancada', MBL rediscute atuação e cogita partido: Movimento que ganhou visibilidade no impeachment de Dilma contabiliza 4 deputados e 2 senadores eleitos. Anna Virginia Balloussier. [S. 1.], 23 jun. 2015. Disponível em: <https://www1.folha.uol.com. br/poder/2018/11/apos-eleger-uma-bancada-mbl-rediscute-atuacao-e-cogita-partido.shtml>. Acesso em: 24 ago. 2020.

FOLHA DE SÃO PAULO. DEM expulsa Arthur Mamãe Falei, pré-candidato do MBL à Prefeitura de São Paulo. Reportagem de Carolina Linhares. São Paulo, nov. 2019. Disponível em: < https://bit.ly/2AQ3gKV>. Acesso em: 03 jul. 2020.

\section{FOLHA DE SÃO PAULO. Grupo apoiado por Luciano Huck, Reno-} vaBR elege 17 de 120 candidatos: Movimento que prega renovação política tinha lista com 30 nomes de maior potencial. Reportagem de Joelmir Tavares. São Paulo, 08 out. 2018. Disponível em: <https://www1.folha.uol.com.br/ poder/2018/10/grupo-apoiado-por-luciano-huck-renovabr-elege-16-de-120-candidatos.shtml>. Acesso em: 08 ago. 2020. 
GAZETA DO POVO. Quem quer ser político? 4 mil candidatos concorrem a bolsa de até R\$ 72 mil. Reportagem de Fernanda Trisotto. Brasil, 06 dez. 2017. Disponível em: <https://www.gazetadopovo.com.br/politica/republica/eleicoes-2018/quem-quer-ser-politico-4-mil-candidatos-concorrem-a-bolsa-de-ate-r-72-mil-1mfw65wz0sk8le8r6viib6fkx/>. Acesso em: 13 jul. 2020.

GOHN, Maria da Glória. A sociedade brasileira em movimento: vozes das ruas e seus ecos políticos e sociais. Caderno CRH, Salvador, v. 27, n. 71, p. 431441, ago. 2014. Quadrimestral.

INSTITUTO DE PESQUISAS E ESTUDOS SOCIAIS. Boletim Mensal. Ano 2, n. 7, fevereiro 1963, n. avulso. Disponível em: < http://sian.an.gov. $\mathrm{br} /$ sianex/consulta/Pesquisa_Livre_Painel_Resultado.asp?v_CodReferencia_ id=1186630\&v_aba=1>. Acesso em: 02 jul. 2020.

INSTITUTO DE PESQUISAS E ESTUDOS SOCIAIS. Livros distribuídos pelo IPES. Disponível em: < http://sian.an.gov.br/sianex/consulta/resultado_pesquisa_new.asp? _ $_{\text {p pesquisa }}=$ com unismo\&v_fundo_colecao $=$. Acesso em: 02 jul. 2020.

INSTITUTO DE PESQUISAS E ESTUDOS SOCIAIS. O que é o IPES?. Rio de Janeiro, 1961. Disponível em: < https://bit.ly/2ClY3uF>. Acesso em: 02 jul. 2020.

INSTITUTO MILLENIUM. Carta de Princípios. Disponível em: < https:/ / www.institutomillenium.org.br/institucional/carta-de-principios/>. Acesso em: 22 jul. 2020.

INSTITUTO MILLENIUM. Etiqueta - Comunismo. Disponível em: $<$ https://www.institutomillenium.org.br/etiqueta/comunismo/>. Acesso em: 22 jul. 2020.

INSTITUTO MILLENIUM. Etiqueta - Investimento Estrangeiro. Disponível em: < https://www.institutomillenium.org.br/etiqueta/investimento-estrangeiro/>. Acesso em: 22 jul. 2020.

INSTITUTO MILLENIUM. Etiqueta - Corrupção. Disponível em: $<$ https://www.institutomillenium.org.br/etiqueta/corrupcao/?a1=60>. Acesso em: 22 jul. 2020.

INSTITUTO MILLENIUM. Quem Somos. Disponível em: < https://www. institutomillenium.org.br/institucional/quem-somos/>. Acesso em: 22 jul. 2020.

MESSAGI JUNIOR, Mário. Outros junhos virão: protestos organizados em rede e as democracias radicalizadas. $1^{a}$ Edição, Curitiba, Kotter Editorial, 2019. 
MOURA, Gabriel Vieira de. A interação entre os Movimentos de Renovação Política e os partidos na dinâmica eleitoral de 2018. 2019. 213 f. Dissertação (Mestrado) - Curso de Ciência Política, Universidade de Brasília, Brasília, 2019. p. 213.

MOVIMENTO BRASIL LIVRE. 100 anos de comunismo: pessoas preferem ir em uma missão quase suicida do que ficar mais um dia sob o regime. 2020. Facebook: MBL. Disponível em: <https://www.facebook.com/mblivre/photos/100-anos-de-comunismo-pessoas-preferem-ir-em-uma-miss $\% \mathrm{C} 3 \% \mathrm{~A} 3 \mathrm{O}-$ -quase-suicida-do-que-fic/740391226085023/>. Acesso em: 09 jul. 2020.

MOVIMENTO BRASIL LIVRE. Movimento pró-corrupção perde força: impeachment está mais perto!. 2020. Facebook: MBL. Disponível em: $<$ https://www.facebook.com /mblivre/posts/357430421047774/>. Acesso em: 23 jul. 2020.

MOVIMENTO BRASIL LIVRE. Propostas aprovadas no Primeiro Congresso nacional do Movimento Brasil Livre. São Paulo, nov. 2015. Disponível em: <https://mbl.org.br/wordpress/wp-content/uploads/2017/05/ propostas-mbl.pdf $>$. Acesso em: 06 jul. 2020.

NOGUEIRA, Marco Aurélio. Partidos, movimentos, democracia: riscos e desafios do século XXI. Journal of Democracy em Português, v. 8, n. 2, p. 24-25, São Paulo, Plataforma Democrática, 2019.

O GLOBO. Votação da reforma da Previdência expõe atritos entre partidos e movimentos de renovação. Reportagem de Miguel Caballero. Brasil, 12 jul. 2019. Disponível em: < https://oglobo.globo.com/brasil/votacao-da-reforma-da-previdencia-expoe-atritos-entre-partidos-movimentos-de-renovacao-23801747>. Acesso em: 04 jun. 2020.

PINHEIRO-MACHADO, Rosana. Amanhã vai ser maior: o que aconteceu com o Brasil e as possíveis rotas de fuga da crise atual. São Paulo: Planeta, 2019.

PODER360. Em $1^{a}$ eleição, movimento RenovaBR elege 16 candidatos: grupo foi fundado em 2017 Promoveu processo seletivo e aulas. [S. 1.], 12 out. 2018. Disponível em: <https://www.poder360.com.br/eleicoes/em-1a-eleicao-movimento-renovabr-elege-16-candidatos/>. Acesso em: 09 ago. 2020.

RÀMIREZ, Hernán. Dinero y sotanas: una perspectiva de la imbricación de la Iglesia católica en el proceso político brasileño (1961-1970) através de las fuentes del Instituto de Pesquisas e Estudos Sociais (IPES). Estudios, n. 42, Rio Grande do Sul, 2019.

RENOVA BRASIL. Quem Somos? 2018. Disponível em: < https://renovabr. org/o-que-fazemos>. Acesso em: 02 jul. 2020. 
RENOVA BRASIL. O que fazemos? 2018. Disponível em: < https:// renovabr.org/o-que-fazemos/>. Acesso em: 01 ago. 2020.

SALGADO, Eneida Desiree. Os princípios constitucionais eleitorais como critérios de fundamentação e aplicação das regras eleitorais: uma proposta. Estudos Eleitorais, v. 6, n. 3, p. 103-129, 2011.

SALGADO, Eneida Desiree. Representação política e o modelo democrático brasileiro. Direito Constitucional Brasileiro, v. 1, São Paulo, Revista dos Tribunais, 2014.

SAVAZONI, Rodrigo. Os novos bárbaros: a aventura política do fora do eixo. Rio de Janeiro: Aeroplano, 2014.

SILVA, Luiz Fernando Zelinski da. Plutocracia em jogo: a reforma do financiamento de campanha e as eleições para prefeito em 2016. Dissertação (Mestrado em Ciências Políticas) - Curso de Pós-graduação em Ciência Política, Universidade Federal do Paraná, Curitiba, 2020.

THE GUARDIAN. Brazil's right on the rise as anger grows over scandal and corruption. Reportagem de Dom Phillips. São Paulo, jul. 2017. Disponível em: < https://bit.ly/3iWMxqe>Acesso em: 04 jul. 2020.

Eneida Desiree Salgado - Doutora em Direito do Estado. Professora Associada do Departamento de Direito Público da Universidade Federal do Paraná. Pesquisadora líder do Núcleo de Investigações Constitucionais. Advogada.

Iago Korello dos Santos - Graduando em Direito pela Universidade Federal do Paraná. Pesquisador do Núcleo de Investigações Constitucionais. Estagiário na Promotoria de Proteção ao Patrimônio Público (MP-PR).

Wesley Alves Bergonzine - Graduando em Direito pela Universidade Federal do Paraná. Pesquisador do Núcleo de Investigações Constitucionais. Estagiário na Procuradoria Regional Eleitoral (PR). 